\title{
Effects of substratum and conspecific adults on the metamorphosis of Chasmagnathus granulata (Dana) (Decapoda: Grapsidae) megalopae
}

\author{
P. Gebauer*, I. Walter, K. Anger \\ Biologische Anstalt Helgoland, Meeresstation. PB: 180, D-27483 Helgoland, Germany
}

Received 7 February 1997; received in revised form 3 June 1997; accepted 12 June 1997

\begin{abstract}
The ability of marine invertebrate larvae to delay their metamorphosis in the absence of adequate environmental cues has been reported for numerous sedentary and sessile species. In the present study, the effect of various substrata and the presence of conspecific adults on the metamorphosis of a mobile species, the crab Chasmagnathus granulata, was evaluated. The duration of the megalopa stage in experiments with six different substrata and in the presence or absence of conspecific adults was compared in a laboratory study. In addition, the influence of natural substrata was compared with that of artificial substrata of similar grain size or texture. In a further experiment, the two most effective cues (natural mud and conspecific adults) were tested as single vs. combined factors. Natural mud and unidentified chemical cues from conspecific adults had the strongest accelerating effects on development duration to metamorphosis. With the exception of nylon threads (artificial filamentous substratum), none of the artificial substrata had a significant effect on the duration of the megalopa stage. Simultaneous exposure to natural mud and water containing chemical cues from conspecific adults accelerated metamorphosis more than each of these factors separately. Megalopae that were reared without a substratum (control) delayed their metamorphosis by 29\% (about 3 days) compared with those in simultaneous contact with natural mud and rearing water of adult conspecifics. The results indicate that the metamorphosis of the megalopa of $C$. granulata is influenced by the presence or absence of environmental stimuli that are associated with the preferred adult habitat. (c) 1998 Elsevier Science B.V.
\end{abstract}

Keywords: Chasmagnathus granulata; Crab; Megalopa; Metamorphosis; Settlement; Substratum

*Corresponding author. Fax: + $494725 / 819369$. 


\section{Introduction}

Specific chemical and/or physical cues trigger settlement and metamorphosis of many sedentary or sessile marine invertebrate larvae (Crisp, 1974; Scheltema, 1974; Hadfield, 1978; Burke, 1983; Rittschof and Bonaventura, 1986; Rittschof and Costlow, 1989; Pechenik, 1990). In the absence of such cues, the larvae delay their metamorphosis for a few hours up to several months (see Pechenik, 1990 for review). This delay should increase the chance that larvae find an adequate habitat for successful settlement, growth and reproduction (Pechenik, 1990). This is crucial for species that, partly or completely, lose their mobility after settlement. The inducing factors for those species are mainly associated with conspecific individuals.

Mobile and non-gregarious species (e.g. most decapod crustaceans) depend less on environmental cues for the induction of settlement and metamorphosis (Chia, 1978). However, there is evidence of some flexibility in the time of metamorphosis, when adequate cues are absent. Laboratory experiments demonstrated that the duration of the megalopa stage of Uca pugilator is shortened by the contact with sediment originating from the habitat of adult conspecifics (Christy, 1989) or in the presence of muddy substratum with adults (O'Connor, 1991). Megalopae of Callinectes sapidus can accelerate the time to metamorphosis by about $10 \%$ if they are exposed to low salinity water from an estuarine salt marsh (Wolcott and De Vries, 1994). The presence of eelgrass has the same effect, presenting the larvae with both a chemical and a textural cue for the induction of metamorphosis (Forward et al., 1994). In the absence of shelter or an adequate substratum, Homarus americanus larvae may delay settlement by more than 2 wks (Botero and Atema, 1982). There is strong evidence that megalopae of Petrolisthes cinctipes and P. eriomerus respond positively to the presence of conspecific adults (Jensen, 1989). Recent experiments by Weber and Epifanio (1996) showed that stimuli related to the preferred adult substrata, as well as the presence of adult conspecifics, can induce metamorphosis in competent megalopae of Panopeus herbstii. Also, Harvey (1996) demonstrated that the time to metamorphosis was affected in two hermit crabs, Pagurus maclaughlinae and Paguristes tortugae, by exposure to adultconditioned water and in another hermit crab, Clibanarius vittatus, by the presence of sediment.

Chasmagnathus granulata is a gregarious, semi-terrestrial species that lives in estuaries where they build burrows on muddy bottoms (Boschi, 1964). Crabs of all sizes can be found in burrows, including juveniles with $<10 \mathrm{~mm}$ carapace width (Spivak et al., 1994) and even smaller recruits (Luppi et al., 1994). Investigations carried out at the Mar Chiquita lagoon (Argentina) suggest that this species follows an export dispersion strategy, in which the first larval stage (Zoea I) leaves the parental environment within the first day after hatching, and the following larval stages develop in coastal waters. The megalopae return to the lagoon for settlement and metamorphosis (Anger et al., 1994).

Based on these life-history characteristics of $C$. granulata, we presumed that the metamorphosis of the megalopa could be induced by habitat-related factors. This hypothesis was tested by examining the duration of the megalopa stage in the presence or absence of different substrata and adult conspecifics. 


\section{Materials and methods}

The larvae of $C$. granulata were obtained from females that were collected from Mar Chiquita lagoon (Argentina) and maintained in the laboratory of the Helgoland Marine Biological Station. The larvae were reared to the Zoea IV stage in 10-1 bottles with gentle aeration at constant temperature $\left(18^{\circ} \mathrm{C}\right)$, salinity $(32 \% \mathrm{o})$ and photoperiod $(12: 12 \mathrm{~h}$ light:dark) in filtered (ca. $1 \mu \mathrm{m})$ sea water. Each experiment began with freshly moulted megalopae $(\leq 15 \mathrm{~h})$ that moulted synchronously and were distributed among the different treatments. During daily water change and feeding (freshly hatched Artemia sp. nauplii), larvae were checked for moults or mortality. Except for the size of cultivation bowls and aeration, megalopae were reared under the same conditions.

\subsection{Experiment 1: effects of natural and artificial substrata}

In Experiment 1, the effects of different natural and artificial substrata on duration of the megalopa stage were tested. Freshly moulted megalopae of $C$. granulata were transferred to unaerated glass bowls containing the test substrata, and reared in groups of 15 larvae each in approximately $390 \mathrm{ml}$ of sea water. The following substrata were tested: muddy sand ( $<100 \mu \mathrm{m}$ grain size; later referred to as 'mud'), medium-fine sand ( $<300 \mu \mathrm{m}$; 'fine sand'), medium-coarse sand ( $>300 \mu \mathrm{m}$; 'coarse sand'), mussel shell fragments, red algae (Ceramium sp.), all originating from the North Sea; nylon gauze (300 $\mu \mathrm{m}$ mesh size), and a sea water control (without any substrata other than the bowl walls). Each bowl contained a layer of ca. $0.8 \mathrm{~cm}$ of substratum, ca. $1.0 \mathrm{~g}$ of algae (wet weight) or a $6.5 \times 8.5-\mathrm{cm}$ piece of gauze. All conditions were tested with 5 replicate bowls, yielding a total of 75 individuals per treatment. Statistical tests revealed no bowl effects in the rates of survival or development.

\subsection{Experiment 2: test for group effects}

To evaluate a possible group effect of other megalopae on the metamorphosis of larvae reared in mass culture (MC), the same set of experiments was carried out simultaneously with larvae from the same hatch in individual culture (IC). This was conducted with 30 megalopae reared individually in 100-ml plastic vials with approximately $80 \mathrm{ml}$ of sea water each, under otherwise identical conditions. Both experiments were carried out twice: July 1994 (Female 1= Hatch 1) and March 1995 (Female $2=$ Hatch 2).

\subsection{Experiment 3: effects of grain size and texture}

Experiment 3 was carried out to examine the importance of grain size and texture of the substratum as a possible physical cue (Female 3). In this experiment, the megalopae were offered either natural or artificial substrata of similar grain size. The natural substrata offered were a ca. $0.8-\mathrm{cm}$ layer of mud, coarse sand, gravel $(3-5 \mathrm{~mm})$, or Cladophora sp. (ca. $1.0 \mathrm{~g}$ wet weight) as a filamentous alga (Ceramium sp. was not available at the time of this experiment). As artificial substrata, irregularly shaped, 
smoothed glass particles of similar grain sizes were used. Bundles of nylon threads were used as an artificial filamentous substratum. Each treatment comprised three replicates with 15 to 20 megalopae each (depending on the availability of larvae), reared in groups with $450 \mathrm{ml}$ of sea water each.

\subsection{Experiment 4: presence of conspecific adults}

In Experiment 4, the influence of the presence of adults on the time to metamorphosis was evaluated (Female 4). Fifteen freshly moulted megalopae were maintained in a sieve (300 $\mu \mathrm{m}$ mesh size) and placed in an aquarium containing 21 of sea water and one adult (three replicates with females, two replicates with males; $26-30 \mathrm{~mm}$ carapace width, 8.7-14.7 g wet weight). Two control conditions, each of them with 75 larvae divided into five replicate groups, were run in this experiment: (1) megalopae reared without a substratum in glass bowls (as described above), and (2) larvae maintained in a sieve that was placed in an aquarium without adults, in order to check for a potential effect of the sieve.

\subsection{Experiment 5: combined vs. single effects of mud and conspecific adults}

Based on the results of Experiments 1 and 4, where natural mud and the presence of adult conspecifics had been identified as the two most effective stimuli, these treatments were combined in Experiment 5 (Female 4). Again, five replicate groups were tested, each with 15 megalopae. They were reared in glass bowls containing ca. $0.8 \mathrm{~cm}$ of mud, 'adult water', both mud and 'adult water', or sea water only as a control treatment. The 'adult water' was obtained by holding individually three females and two males (25-30 mm carapace width, 6.2-18.9 g wet weight) in 21 of sea water each for $24 \mathrm{~h}$. The 'adult water' of these five adults was mixed before using it in experiments.

\subsection{Statistical analysis}

Effects of different experimental conditions were analysed by comparing the mean duration of the megalopa stage, and the cumulative percentage of megalopae undergoing metamorphosis during the experiment. A statistical analysis of the temporal progression of the metamorphosis was carried out for two different days of each experiment. Cumulative percentages were compared on the day when $50 \%$ of the larvae in the treatment with the fastest development had undergone metamorphosis and on the day when, in all treatments, at least $50 \%$ of the megalopae had moulted to the first juvenile. All statistical analysis followed standard techniques (Sokal and Rohlf, 1995).

Zero percent and 100\% were weighted as suggested by Snedecor and Cochran (1967, p. 327) for sample sizes $<50$; percentages were then arcsin transformed for statistical analysis. Normality and variance homogeneity were tested by means of the Kolmogorov-Smirnov, and the Levene median test, respectively. When the data complied with the requirements for parametrical tests, a one-way Analysis of Variance (ANOVA) was used, otherwise the Kruskal-Wallis $H$-test was applied. Multiple comparisons were done comparing data from the control treatment (sea water) with the Dunnett test $\left(q^{\prime}\right)$ 
for identical sample sizes, or using the Dunn test $(Q)$ for data sets of different size and non-normal distribution. Differences were considered to be significant when $P \leq 0.05$. For Experiments 3, 4 and 5 multiple comparisons were carried out with StudentNewman-Keuls test (SNK) $(q)$ for equal sample sizes, or with Dunn's test for different sample sizes and a non-normal distribution. For Experiment 2, the Mann-Whitney U-test with the modifications suggested by Sokal and Rohlf (1995, p. 430) was used. The independence $R \times C$ test (using the $G$ statistic with William's correction) was used to analyse effects of treatments on larval mortality.

\section{Results}

\subsection{Experiment 1: effects of natural and artificial substrata}

Under identical conditions, the development of the megalopae from Female 1 took significantly longer than that of Female $2(P<0.001)$ with $17.6 \pm 2.1$ (mean \pm SD) and $14.4 \pm 2.5$ days, respectively, in the control experiments without substratum. Therefore, the results for the two hatches were analysed separately.

In Experiment 1, natural mud had consistently the strongest effect on metamorphosis (Fig. 1). On mud, the mean duration of the megalopa stage was $14.7 \pm 1.4$ vs. $17.6+2.1$ days in the control $(P<0.001$, Female 1; Fig. 1a), and $12.1 \pm 1.5$ vs. $14.4+2.5$ days $(P<0.001$, Female 2; Fig. 1b). The development time of the megalopa was not affected by the other substrata $(P>0.05)$, except that for offspring of Female 2, megalopae on mussel shell fragments had a significantly shorter development than the control group (Fig. 1b). Analysis of cumulative moulting frequency showed that $50 \%$ metamorphosis occurred about 2 days earlier on mud (Fig. 1c, d). By Days 15 (Female 1) and 12 (Female 2), nearly $65 \%$ of the larvae had undergone metamorphosis on mud, while the percentage of metamorphosis in the controls reached only 6 and 20\%, respectively, $(P<0.001$; Fig. 1e, f). Two days later (Day 17 and 14), when $\geq 50 \%$ of the individuals had metamorphosed in all treatments, the percentage of metamorphosis in the mud was still significantly higher than in the other treatments $(P<0.05$; Fig. 1e; f). In general, however, the treatments did not affect the survival of the megalopa. Only in Female 2, the mortality of megalopae reared on mud was significantly lower than that with other substrata $(P<0.05$; Table 1$)$.

\subsection{Experiment 2: test for group effects}

Pairwise comparisons of same treatments showed (with two exceptions) no significant differences in the duration of the megalopa stage under conditions of either mass-rearing or individual culture $(P>0.05$, Table 2$)$. Hence, the rearing method had no significant effect on the duration of megalopa development, although individually maintained megalopae showed a higher survival than those in mass culture (Table 1). 

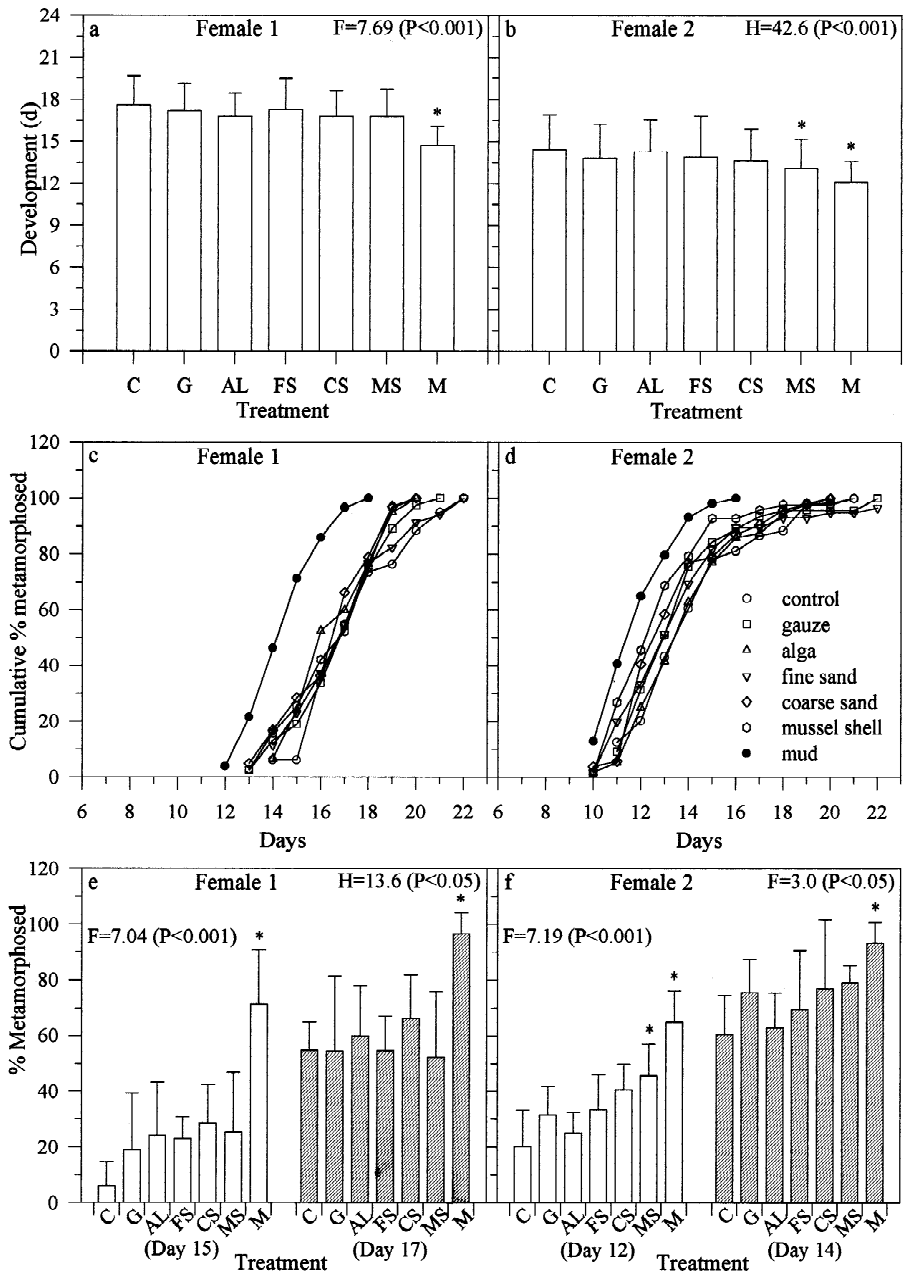

Fig. 1. (a-b) Mean ( + SD) duration of development (days) of Chasmagnathus granulata on different substrata: sea water control (C), gauze (G), algae (AL), fine sand (FS), coarse sand (CS), mussel shell fragments (MS), mud (M). (c-d) Cumulative percentage of metamorphosed individuals. (e-f) Left part of graphs, open bars: percent of metamorphosed megalopae (mean $+\mathrm{SD}$ ) on the day when, in the treatment with the fastest development a minimum of 50\% had passed through metamorphosis; right part, hatched bars: percent metamorphosed on the day when, in the treatment with the slowest development a minimum of $50 \%$ of metamorphosis was reached; left column of graphs $(\mathrm{a}-\mathrm{c}-\mathrm{e})$ megalopae from Female 1, right column of graphs (b-d-f) Female 2. $n=75$ megalopae divided in 5 replicates per treatment. $H$ : Kruskal-Wallis statistic, $F: F$ statistic, $P$ : probability, $*$ : significantly different from control $(P<0.05)$, based on multiple comparisons.

\subsection{Experiment 3: effects of grain size and texture}

Only nylon threads caused a significantly shorter development than in the control megalopae $(13.8 \pm 2.5$ vs. $16.3 \pm 4.3$ days; $P<0.01)$. The development time on artificial 
Table 1

Effect of different treatments on mortality of Chasmagnathus granulata

\begin{tabular}{|c|c|c|c|c|c|c|c|c|}
\hline \multicolumn{9}{|l|}{ Mortality (\%) } \\
\hline \multirow{2}{*}{$\begin{array}{l}\text { Female } \\
\text { Experiment } 2\end{array}$} & \multicolumn{4}{|l|}{1} & \multicolumn{4}{|l|}{2} \\
\hline & $\mathrm{MC}$ & IC & $G$ & Significance & $\mathrm{MC}$ & IC & $G$ & Significance \\
\hline Control & 64.0 & 30.0 & 9.94 & b & 35.0 & 17.0 & 3.50 & n.s. \\
\hline Gauze & 52.0 & 27.0 & 5.65 & a & 40.0 & 17.0 & 5.56 & a \\
\hline Alga & 71.0 & 43.0 & 6.59 & $\mathrm{a}$ & 33.0 & 20.0 & 1.88 & n.s. \\
\hline Fine sand & 47.0 & 17.0 & 8.87 & b & 29.0 & 21.0 & 0.58 & n.s. \\
\hline Coarse sand & 61.0 & 30.0 & 8.43 & b & 27.0 & 28.0 & 0.01 & n.s. \\
\hline Mussel shell & 60.0 & 40.0 & 3.39 & n.s. & 38.0 & 27.0 & 1.09 & n.s. \\
\hline Mud & 59.0 & 27.0 & 8.88 & b & 15.0 & 21.0 & 0.51 & n.s. \\
\hline
\end{tabular}

Experiment 1

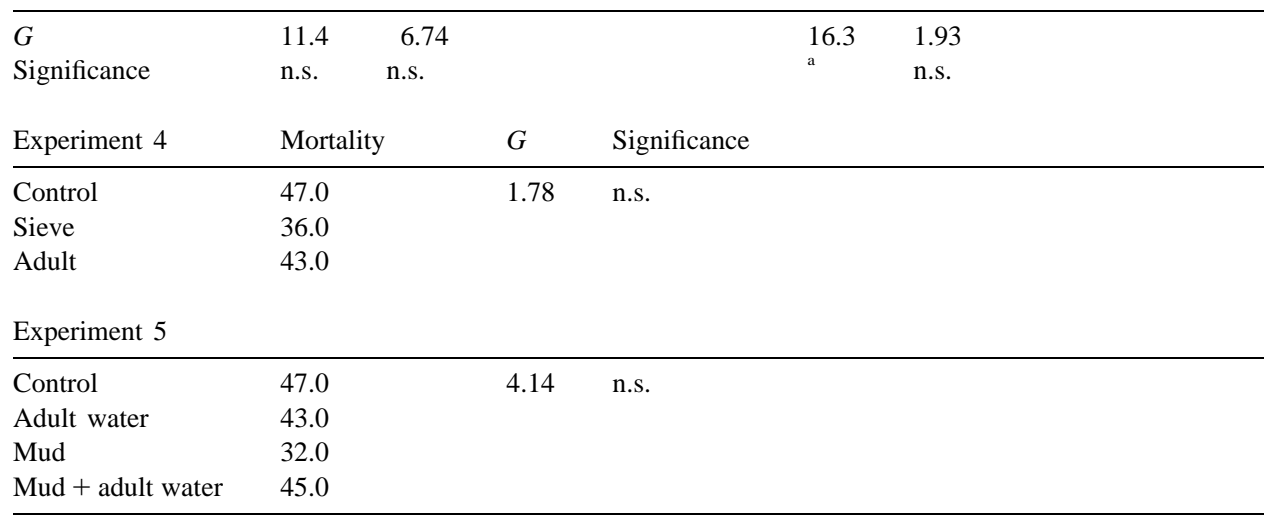

MC: mass culture, IC: individual culture, $G$ : statistic of $G$-test for independence. Significance: $P>0.05$ not significant (n.s.),

${ }^{\mathrm{a}} P \leq 0.05 ;{ }^{\mathrm{b}} P \leq 0.01$ significant.

mud, sand and gravel did not differ significantly from the control. However, in this experiment, all natural substrata offered had a significant accelerating effect on metamorphosis $(P<0.001 ;$ Fig. 2). Again, the megalopae exposed to natural mud showed a significantly shorter duration of development (Fig. 2d).

\subsection{Experiment 4: presence of conspecific adults}

The presence of conspecific adults had a clear effect on the duration of the megalopa stage (Fig. 3). With adults present, the mean duration of the megalopa was $10.9 \pm 1.1$ vs. $13.2 \pm 1.8$ days in the control without substratum $(P<0.001 ;$ Fig. 3a). The delay of moulting in the two control groups (without adults, but with or without a sieve) was on average 2.3 days $(21 \%)$ as compared with the treatment with adults. After 11 days, significantly more megalopae had metamorphosed in the presence of adults $(74 \pm 23 \%)$ than in the controls $(22 \pm 19$ and $22 \pm 12 \%)(P<0.01$; Fig. 3b). This was also the case on 
Table 2

Influence of the rearing method mass culture vs. individual culture on the development of Chasmagnathus granulata

\begin{tabular}{|c|c|c|c|c|c|}
\hline \multirow{2}{*}{$\begin{array}{l}\text { Treatment } \\
\text { Female } 1\end{array}$} & \multicolumn{2}{|c|}{ Mass culture } & \multicolumn{3}{|c|}{ Individual culture } \\
\hline & Mean & SD & Mean & SD & $t s$-value \\
\hline Control & 17.6 & 2.06 & 17.2 & 1.88 & 0.19 \\
\hline Gauze & 17.2 & 1.96 & 16.8 & 2.38 & 0.80 \\
\hline Alga & 16.8 & 1.63 & 18.3 & 2.52 & 0.49 \\
\hline Fine sand & 17.3 & 2.19 & 16.4 & 1.92 & 1.18 \\
\hline Coarse sand & 16.8 & 1.81 & 16.0 & 2.62 & 1.88 \\
\hline Mussel shell & 16.8 & 1.93 & 17.4 & 2.04 & 0.06 \\
\hline Mud & 14.7 & 1.37 & 15.5 & 2.28 & 0.81 \\
\hline
\end{tabular}

Female 2

\begin{tabular}{llllll}
\hline Control & 14.4 & 2.52 & 15.4 & 2.02 & $2.11^{\mathrm{a}}$ \\
Gauze & 13.8 & 2.42 & 13.9 & 1.78 & 0.56 \\
Alga & 14.2 & 2.31 & 14.9 & 2.80 & 0.90 \\
Fine sand & 13.9 & 2.90 & 14.0 & 2.96 & 0.80 \\
Coarse sand & 13.7 & 2.23 & 14.0 & 2.96 & 0.03 \\
Mussel shell & 13.1 & 2.05 & 13.8 & 2.30 & 1.30 \\
Mud & 12.1 & 1.47 & 13.3 & 1.79 & $2.03^{\mathrm{a}}$ \\
\hline
\end{tabular}

Mean development duration (days) of megalopae (mean \pm SD) on different substrata; $t s$-value: Mann-Whitney $U$-statistic for tied variates and sample size $n_{1}>20$ (Sokal and Rohlf, 1995; p. 430); ${ }^{a} P \leq 0.05$

Day $13(P<0.001$. Fig. 3c). The sieve alone had no effect on metamorphosis. Survival did not differ significantly among treatments (Table 1).

\subsection{Experiment 5: combined vs. single effects of mud and conspecific adults}

Natural mud and unidentified chemical cues from conspecific adults in combination had a stronger effect on metamorphosis than each of these factors alone (Fig. 4). Megalopae exposed to a combination of 'adult water' (water in which an adult had been present for $24 \mathrm{~h}$ ) with natural mud underwent the metamorphic moult after $10.2 \pm 1.3$ days. With 'adult water' or mud alone, the mean duration of the megalopa stage was $11.6 \pm 1.6$ and $11.6 \pm 1.7$ days $(P>0.05)$, respectively, while the control megalopae took $13.2 \pm 1.8$ days (Fig. $4 \mathrm{a} ; P<0.001$ ). Analysis of cumulative moulting frequency showed that $50 \%$ of metamorphosis occurred after about 10 days of exposure to 'mud + adult water', after about 12 days of exposure to 'adult water' or mud alone, and after about 13 days in the control treatment (Fig. 4b). On Days 10 and 13, the proportion of larvae having undergone metamorphosis in the treatment with combined cues was significantly higher than in all other treatments. The frequency of metamorphosis was similar in the treatments with mud or 'adult water' alone, but lower in the control (Fig. 4c, d). Compared with the combined cues, the delay of metamorphosis was $29 \%$ in the control group and $14 \%$ for the single stimulus. The mortality did not differ significantly among the different treatments (Table 1). 

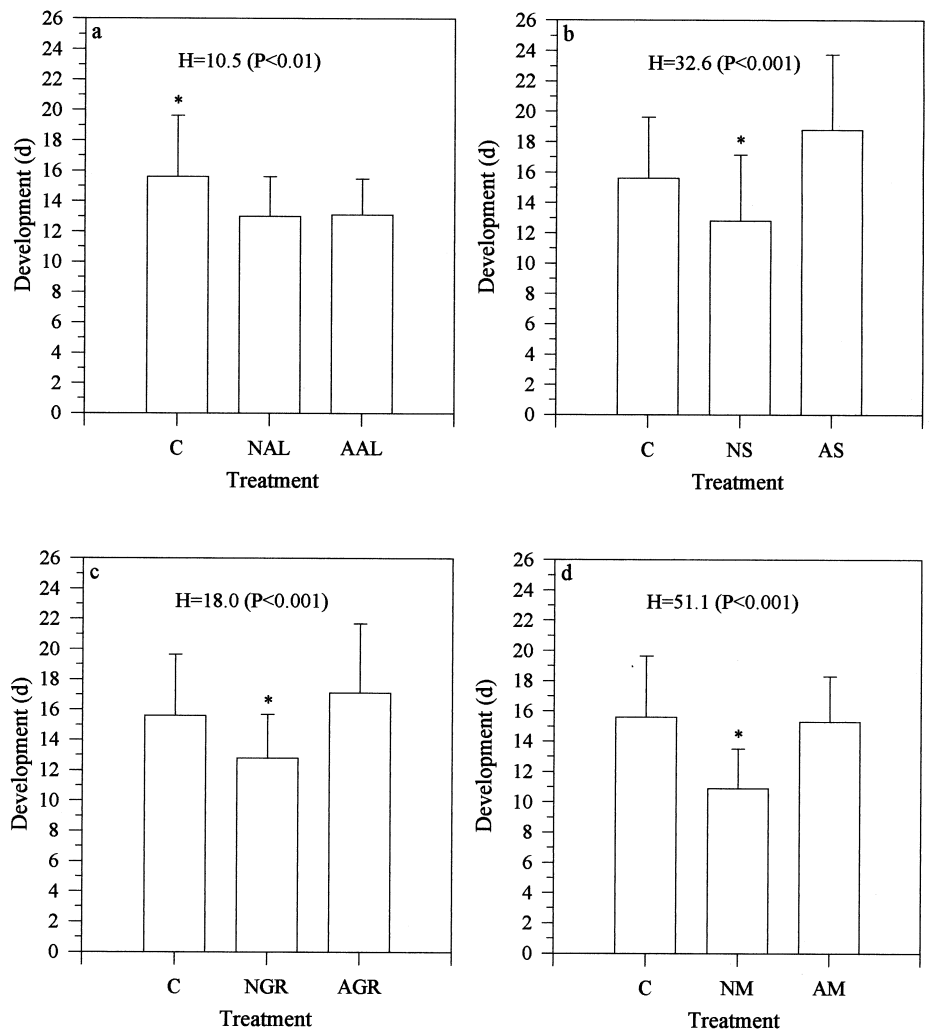

Fig. 2. Duration of megalopa development of Chasmagnathus granulata on artificial and natural substrata (mean + SD): control (C), natural algae (NAL), artificial algae (AAL), natural sand (NS), artificial sand (AS), natural gravel (NGR), artificial gravel (AGR), natural mud (NM) and artificial mud (AM). $n$ (artificial substrata) $=60$ megalopae divided in 3 replicates; $n$ (natural substrata) $=45$ larvae divided in 3 replicates. *: significantly different from other treatments $(P<0.05)$. For further explanation see Fig. 1.

\section{Discussion}

In our experiments, environmental stimuli altered the timing of metamorphosis of Chasmagnathus granulata megalopae reared under laboratory conditions. The duration of megalopa development was characterized using both its mean duration and the cumulative percentage of metamorphosed individuals over time. Both criteria yielded similar results but the most conspicuous differences between treatments occurred during the earlier phase of the experiment, before more than about $50 \%$ of the larvae exposed to the most effective stimulus had undergone metamorphosis. There were significant differences in the absolute duration of the development between megalopae from different females. However, the patterns of response to the tested stimuli were the same, independent of the origin of the megalopae.

Metamorphosis occurred earlier in the presence of the muddy substratum and with chemical cues from adult conspecifics than with other substrata or sea water alone. The 

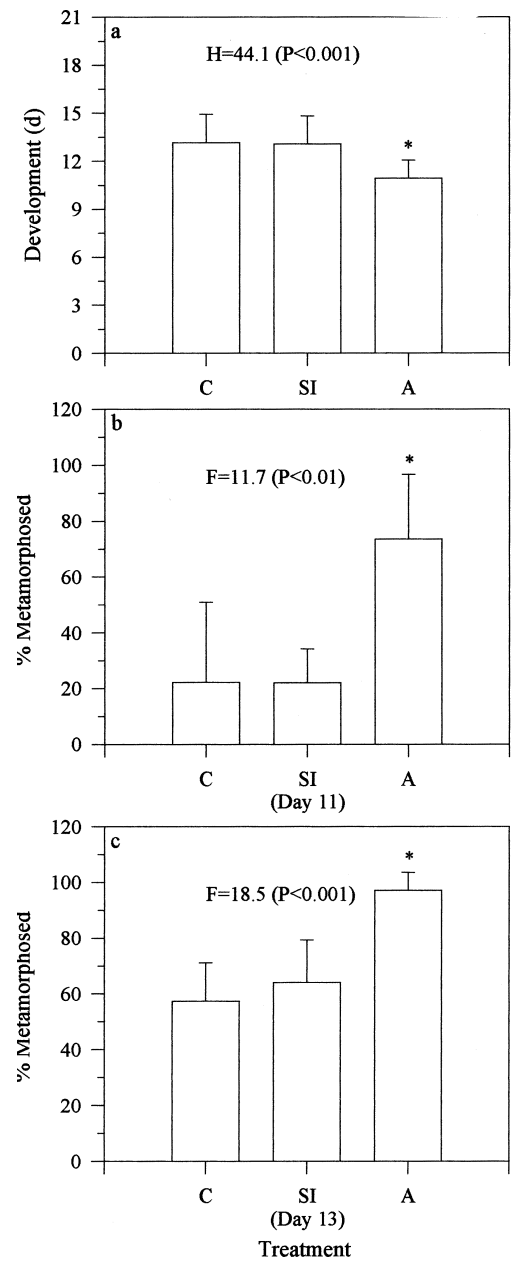

Fig. 3. Effect of adult of Chasmagnathus granulata on (a) mean ( $+\mathrm{SD})$ duration of development in different treatments. (b) Percent of metamorphosed megalopae (mean + SD) on the day when, in the treatment with the fastest development a minimum of 50\% had undergone metamorphosis. (c) Percent metamorphosed on the day when, in the treatment with the slowest development, a minimum of $50 \%$ of metamorphosis was reached; $n=75$ megalopae divided in 5 replicates per treatment, C: control, SI: sieve, A: adult. *: significantly different from other treatments $(P<0.05)$. For further explanation see Fig. 1.

strongest stimulus was provided by a combination of those two factors. In absence of these stimuli, the majority of the larvae delayed their metamorphosis by a maximum of 29\%. Later, the larvae metamorphosed spontaneously, as observed also in other species (Pechenik, 1980, 1986; Kempf, 1981). However, unlike some gastropod and echinoderm species, the megalopae of $C$. granulata can delay its metamorphosis by only few days. Apparently, the reduction in postsettlement (juvenile) fitness of crabs could be too great to allow for a longer delay and hence, selection may favour a relatively short period of 

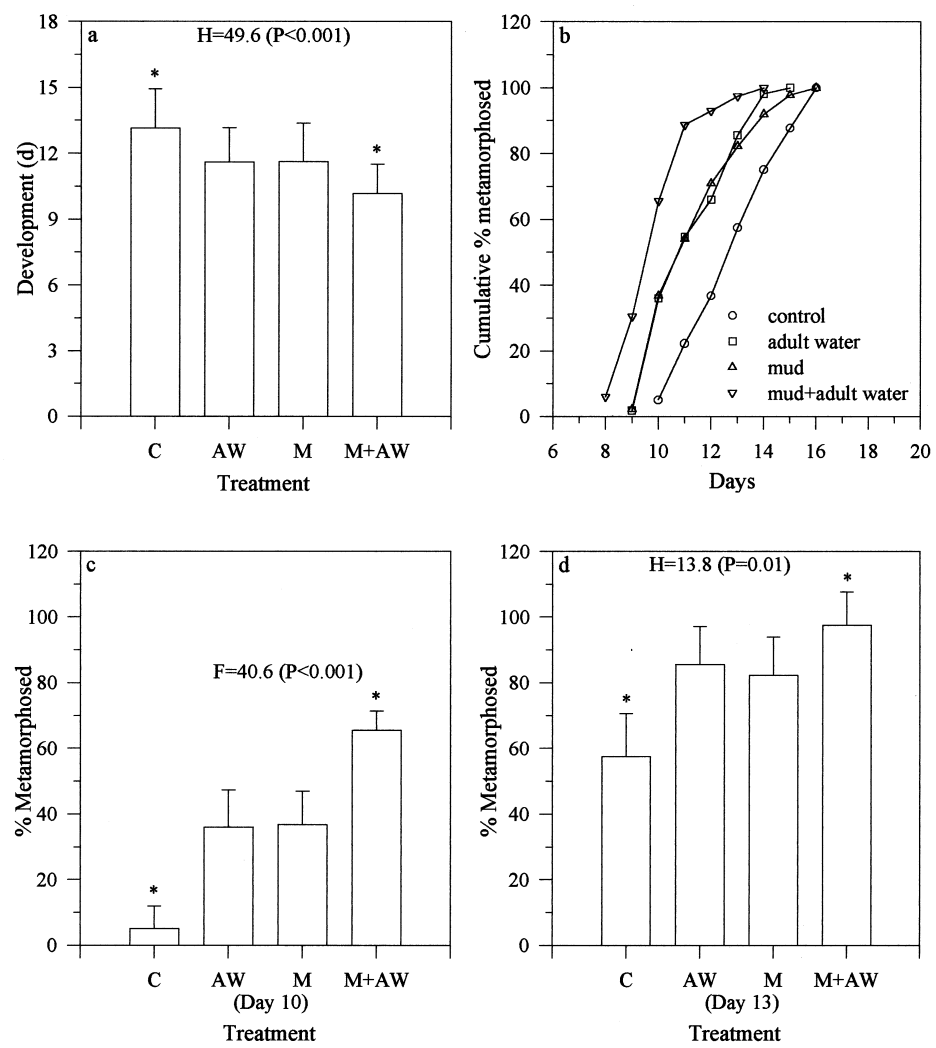

Fig. 4. Effect of combined cues on (a) mean ( + SD) duration of development of Chasmagnathus granulata in different treatments. (b) Cumulative percentage of metamorphosed larvae. (c) Percent of metamorphosed megalopae (mean + SD) on the day when, in the treatment with the fastest development a minimum of $50 \%$ had passed through metamorphosis. (d) Percent of metamorphosed megalopae (mean + SD) on the day when, in the treatment with the slowest development a minimum of $50 \%$ of metamorphosis was reached; $n=75$ megalopae divided in replicates per treatment, C: control, AW: 'adult water', M: mud, M + AW: mud + 'adult water'. *: significantly different from other treatments $(P<0.05)$. For further explanation see Fig. 1.

metamorphic competence. This may be a common trait of brachyuran larvae, where no cases of extremely long delays of metamorphosis have been reported in the literature. Only in a few cases (10\%) was the megalopa stage prolonged to 16 days. These results indicate the ability of $C$. granulata to alter the time of their metamorphosis, depending on the presence or absence of habitat-related stimuli.

C. granulata is a gregarious, semi-terrestrial species that digs burrows in the muddy bottoms of salt marshes, coastal lagoons and estuaries in Brazil and Argentina (Boschi, 1964). Anger et al. (1994) suggest that $C$. granulata has an export strategy of dispersal. For this type of dispersal, the ability to respond to stimuli that indicate the preferred habitat of the species appears advantageous, including a certain flexibility of timing the metamorphic moult. Theoretically, the megalopae should have a better chance of returning to the lagoon before the metamorphic moult, and hence, a lower probability of 
re-exportation from the favourable habitat, if they can delay or accelerate their metamorphosis according to the presence or absence of those stimuli. This ability has recently also been reported for other mobile crustaceans with similar dispersal strategies or specific habitat requirements. Substances released by conspecifics should be relevant stimuli indicating an adequate habitat (Jensen, 1989). Also, low salinity and estuarine vegetation (Wolcott and De Vries, 1994; Forward et al., 1994, 1996), or substratumrelated cues (Christy, 1989; Harvey, 1996; Weber and Epifanio, 1996) have been identified as effective cues.

In the present study, natural mud was the most effective substratum inducing metamorphosis in the megalopa of $C$. granulata. Mussel shell fragments were also effective in one of the experiments, but their effect was less clear. In Experiment 3, natural sand and gravel showed a moderate effect as well. However, artificial substrata of the same grain size had no influence on the metamorphic moult. This suggests that, for sediment substrata, characteristics other than grain size or shape are relevant for the induction of metamorphosis (Pawlik, 1992), the specific-biofilm covering the substrata, for example, as suggested by Weber and Epifanio (1996) for Panopeus herbstii. However, all natural substrata employed in these experiments originated from the North Sea, not from the original habitat of the species. Consequently, the chemical stimulus associated with the substrata was probably of a more general type, such as the bacterial film that is present on all marine surfaces. It is possible that if the utilized substrata had originated from the natural habitat of this species, the effect on duration of development would have been the same or stronger than with the substrata from North Sea. In the case of mud, physical characteristics such as adhesiveness of the particles and penetrability of the substratum could also be important, as these qualities should influence the building of burrows as megalopae were observed to dig in the sediment even before metamorphosis. Our results with fine-grain artificial substrata, however, suggest that these physical traits may be less important. Filamentous substrata were an exception, as nylon threads showed the same effectiveness as natural filamentous algae (Cladophora sp.).

This study provides evidence that the megalopae of $C$. granulata moult earlier to the first crab instar in response to the presence of conspecific adults. There was, however, no clear evidence for a mutual induction of metamorphosis by conspecific megalopae. This corresponds with observations in the field that newly settled recruits occur mainly in zones with a high abundance of adult C. granulata (Spivak et al., 1994; Luppi et al., 1994). Similar effects of adults on metamorphosis have been reported for Petrolisthes cinctipes and P. eriomerus (Jensen, 1989), Uca pugilator (O'Connor, 1991) and, to some extent, for Panopeus herbstii (Weber and Epifanio, 1996). Although in an omnivorous species like $C$. granulata, settlement within a dense patch of adult conspecifics bears a risk of cannibalism, this risk appears to be lower than a settlement in an inadequate habitat, indicated by the absence of an adult population (Jensen, 1989).

Considering each factor separately, mud and water-soluble exudates from conspecific adults had a similar influence on the duration of the megalopa stage. A combination of both stimuli, however, resulted in an even stronger effect. Similar results have also been reported for other soft-sediment dwelling organisms (Suer and Phillips, 1983; O'Connor, 1991). One possible explanation could be a binding of water-soluble conspecific cues on 
the surface of the mud particles and thus, a concentration of such substances on the surface of the substratum. As another explanation, a simple synergism of two, in principle, independent factors is conceivable.

In summary, the results of this study show that the metamorphosis of the megalopa of C. granulata can be stimulated by exogenous cues, which are closely related to the habitat of the species. Thus, the distribution and abundance of this species may be determined by the level of settlement as well as processes that occur after settlement, such as differential mortality, migration, predation and/or competence of juveniles and adults. Responding to indicative stimuli, the megalopae appear capable of actively selecting their site of settlement and hence, their future habitat.

\section{Acknowledgements}

The first author acknowledges a research grant from the Biologische Anstalt Helgoland. We are grateful to three anonymous reviewers who helped to improve this paper.

\section{References}

Anger, K., Spivak, E., Bas, C., Ismael, D., Luppi, T., 1994. Hatching rhythms and dispersion of decapod crustacean larvae in a brackish coastal lagoon in Argentina. Helgoländer Meeresuntersuchungen 48, 445-466.

Boschi, E.E., 1964. Los crustáceos decápodos brachyura del litoral bonaerense (R. Argentina) (The Crustacea Decapoda Brachyura of the littoral of the province of Buenos Aires, Argentina). Boletín del Instituto de Biología Marina Mar del Plata 6, 1-99.

Botero, L., Atema, J., 1982. Behavior and substrate selection during larval settling in the lobster Homarus amaericanus. J. Crustac. Biol. 2, 59-69.

Burke, R.D., 1983. The induction of metamorphosis of marine invertebrate larvae: stimulus and response. Can. J. Zool. 61, 1701-1719.

Chia, F.S., 1978. Perspectives: settlement and metamorphosis of marine invertebrate larvae. In: Chia, F.S., Rice, M.E. (Eds.), Settlement and Metamorphosis of Marine Invertebrate Larvae. Elsevier, New York, pp. 283-285.

Christy, J.H., 1989. Rapid development of megalopae of the fiddler crab Uca pugilator reared over sediment: implications for models of larval recruitment. Mar. Ecol. Prog. Ser. 57, 259-265.

Crisp, D.J., 1974. Factors influencing the settlement of marine invertebrate larvae. In: Grant, P.T., Mackie, A.M. (Eds.), Chemoreception in Marine Organisms. Academic Press, London, pp. 177-265.

Forward, Jr. R.B., Frankel, D.A.Z., Rittschof, D., 1994. Molting of megalopae from the blue crab Callinectes sapidus: effects of offshore and estuarine cues. Mar. Ecol. Prog. Ser. 113, 55-59.

Forward, Jr. R.B., De Vries, M.C., Rittschof, D., Frankel, D.A.Z., Bischoff, J.P., Fisher, C.M., Welch, J.M., 1996. Effects of environmental cues on metamorphosis of the blue crab Callinectes sapidus. Mar. Ecol. Prog. Ser. 131, 165-177.

Hadfield, M.G., 1978. Metamorphosis in marine molluscan larvae: an analysis of stimulus and response. In: Chia, F.S., Rice, ME. (Eds.), Settlement and Metamorphosis of Marine Invertebrate Larvae. Elsevier, New York, pp. 165-175.

Harvey, A.W., 1996. Delayed metamorphosis in Florida hermit crabs: multiple cues and constraints (Crustacea: Decapoda: Paguridae and Diogenidae). Mar. Ecol. Prog. Ser. 141, 27-36. 
Jensen, G.C., 1989. Gregarious settlement by megalopae of the porcelain crabs Petrolisthes cinctipes (Randall) and P. eriomerus Stimpson. J. Exp. Mar. Biol. Ecol. 131, 223-231.

Kempf, S.C., 1981. Long-lived larvae of the gastropod Aplysia juliana: Do they disperse and metamorphose or just slowly fade away?. Mar. Ecol. Prog. Ser. 6, 61-65.

Luppi, T., Spivak, E., Anger, K., 1994. La coexistencia de dos especies de cangrejo en el ecosistema del cangrejal: estudio comparative del asentamiento y el reclutamiento (The coexistence of two crab species in the 'cangrejal' ecosystem: Comparative study of settlement and recruitment). In: II Taller Sobre Cangrejos y Cangrejales. Facultad de Ciencias Exactas y Naturales. Universidad de Mar del Plata, Argentina, p. 55.

O'Connor, N.J., 1991. Flexibility in timing of the metamorphic molt by fiddler crab megalopae Uca pugilator. Mar. Ecol. Prog. Ser. 68, 243-247.

Pawlik, J.R., 1992. Chemical ecology of the settlement of benthic marine invertebrates. Oceanogr. Mar. Biol. Annu. Rev. 30, 273-335.

Pechenik, J.A., 1980. Growth and energy balance during the larval lives of three prosobranch gastropods. J. Exp. Mar. Biol. Ecol. 44, 1-28.

Pechenik, J.A., 1986. Field evidence for delayed metamorphosis of larval gastropods: Crepidula plana Say, $C$. fornicata (L.), and Bittium alternatum (Say). J. Exp. Mar. Biol. Ecol. 97, 313-319.

Pechenik, J.A., 1990. Delayed metamorphosis by larvae of benthic marine invertebrates: does it occur? Is there a price to pay?. Ophelia 32, 63-94.

Rittschof, D., Bonaventura, J., 1986. Macromolecular cues in marine systems. J. Chem. Ecol. 12, 1013-1023.

Rittschof, D., Costlow, J.D., 1989. Surface determination of macroinvertebrate larval settlement. In: Klekowski, R.Z., Styczynska-Jurewicz, E., Falkowski, L. (Eds.), Proceedings of the Twenty-first European Marine Biology Symposium, Zaklad Narodowy im. Ossolinskich-Wydawnictwo, Wroclaw, Poland, pp. $155-163$.

Scheltema, R.S., 1974. Biological interactions determining larval settlement of marine invertebrates. Thalassia Jugoslavica 10, 263-296.

Snedecor, G.W., Cochran, W.G., 1967. Statistical Methods. The Iowa State University Press Ames, USA.

Sokal, R.R., Rohlf, F.J., 1995. Biometry. The Principles and Practice of Statistics in Biological Research, 3rd ed. W.H. Freeman and Co., New York.

Spivak, E., Anger, K., Luppi, T., Bas, C., Ismael, D., 1994. Distribution and habitat preferences of two grapsid crab species in Mar Chiquita Lagoon (Province of Buenos Aires Argentina). Helgoländer Meeresuntersuchungen 48, 59-78.

Suer, A.L., Phillips, D.W., 1983. Rapid, gregarious settlement of the larvae of the marine echiuran Urechis caupo Fisher and MacGinitie 1928. J. Exp. Mar. Biol. Ecol. 67, 243-259.

Weber, J.C., Epifanio, C.E., 1996. Response of mud crab (Panopeus herbstii) megalopae to cues from adult habitat. Mar. Biol. 126, 655-661.

Wolcott, D.L., De Vries, M.C., 1994. Offshore megalopae of Callinectes sapidus: depth of collection, molt stage and response to estuarine cues. Mar. Ecol. Prog. Ser. 109, 157-163. 